\section{Potassium and the anaesthetist}

\section{Potassium regulation}

An adult ingests about $1 \mathrm{mEq} \cdot \mathrm{kg}^{-1}$ of $\mathrm{K}^{+}$per day. Nearly complete absorption occurs in the ileum. Ninety-eight per cent of absorbed $\mathrm{K}^{+}$is pumped into the cells, with the muscle cells forming the largest reservoir. Thus, while the serum $\mathrm{K}^{+}$concentration is usually $3.5-5 \mathrm{mEq} \cdot \mathrm{L}^{-1}$, the intracellular concentration is about $150 \mathrm{mEq} \cdot \mathrm{L}^{-1}$ Potassium balance is maintained by several regulatory mechanisms.

The major regulatory organ is the kidney. The distal tubule cells either absorb or secrete $\mathrm{K}^{+}$depending on the presence or absence of aldosterone. Aldosterone is released whenever serum $\mathrm{K}^{+}$rises. Aldosterone stimulates secretion of $\mathrm{K}^{+}$and resorption of either $\mathrm{Na}^{+}$or $\mathrm{H}^{+}$, Although the kidney is the major excretory organ, extrarenal mechanisms of $\mathrm{K}^{+}$modulation are extremely important to the anaesthetist.

I believe the most important extrarenal modulator is the $\mathrm{N}-\mathrm{K}$ ATPase pump. This enzyme pumps $\mathrm{K}^{+}$into the cell and pumps $\mathrm{Na}^{+}$out of the cell. The pump is under adrenergic control; beta ${ }_{2}$ stimulation activates the pump and alpha ${ }_{1}$ stimulation inhibits the pump. Adrenergic effects are responsible for $\mathrm{K}^{+}$shifts incurred at times of stress. Also, exogenous compounds such as terbutaline and ritodrine are known to induce acute hypokalaemia.

Another extrarenal modulator is insulin. If $\mathrm{K}^{+}$rises substantially and rapidly, insulin is secreted into the portal circulation. At the liver, insulin induces $\mathrm{K}^{+}$to enter hepatocytes. The pancreato-hepatic axis constitutes one of the normal daily control mechanisms for serum $\mathrm{K}^{+}$.

A much implicated cxtrarenal mechanism of $\mathrm{K}^{+}$control is $\mathrm{pH}$. The magnitude and direction of $\mathrm{K}^{+}$flux is determined by more than just the $\mathrm{pH}$. Potassium flux depends on the organ involved and on the aetiology of the $\mathrm{pH}$ change, e.g., during acute respiratory acidosis, $\mathrm{K}^{+}$leaves skeletal muscle cells, but enters cardiac cells. Organic acids (e.g., lactic acid) do not appear to change $\mathrm{K}^{+}$levels. Most probably, acid base changes alone cause only mild changes in serum $\mathrm{K}^{+}$; changes much less than the quoted figure of $0.5 \mathrm{mEq} \cdot \mathrm{L}^{-1} \mathrm{~K}^{+}$per 0.1 unit of $\mathrm{pH}$.

\section{Hypokalaemia}

Hypokalaemia is most often due to excessive $\mathrm{K}^{+}$losses. These losses may be gastrointestinal (e.g., vomiting, nasogastric suction, bowel obstruction) or renal (e.g., diuretics, hyperaldosteronism). However, hypokalaemia
Terry Vitez

may occur without losing $\mathrm{K}^{+}$. In these instances, $\mathrm{K}^{+}$is shifted from plasma into cells. Dramatic acute shifts of $\mathrm{K}^{+}$can occut during maximal adrenal stimulation (e.g., trauma) or administration of beta $a_{2}$ agonists.

Hypokalaemia is thought to increase automaticity, conductivity, and excitability of the heart. These expectations seem confirmed by classical ECG findings: ST segment depression, flattened $T$ waves, $U$ waves, tachycardia or ectopic beats. Based on these considerations, anecdotal reports and limited animal experimentation, hypokalaemia has been thought to make the heart more susceptible to dysrhythmias, digitalis and hypoxia. However, there is little evidence as to when hypokalaemia becomes a problem. The only prospective intraoperative human study performed shows no evidence that chronic hypokalaemia predisposes patients to intraoperative dysrhythmias. There are no data about the postoperative period. There is no evidence that hypokalaemia affects myocardial contractility.

The following paragraphs contain my opinions on when and how to manage hypokalaemia.

The decision of when to treat hypokalaemia should rest on the entire clinical situation, not just the potassium level. Acute losses of potassium may be the only aetiologies that require aggressive therapy. Circumstances which weigh for replacement are the presence of serious preoperative dysrhythmias, digitalis therapy, concomitant administration of aminophylline or a beta $a_{2}$ agonist.

The key to treating hypokalaemia is to interrupt its cause. Potassium therapy is not benign. Diuretic therapy may increase the risk of hyperkalaemia during replacement. Potassium should be infused through a peripheral IV with a mechanical infusion device. Oliguria and low cardiac output states are relative contraindications for potassium infusions. Potassium infusions should not exceed $40 \mathrm{mEq} \cdot \mathrm{L}^{-1}$ concentrations. Infusion rates should not exceed $10-20 \mathrm{mEq} \cdot \mathrm{hr}^{-1}$. Significant repletion may require two days of therapy. Magnesium may be required to facilitate renal resorption and intracel lular transport of potassiun.

When anaesthetizing a hypokalaemic patient, dysthyth* mias are not the only items of concern. Hypokalaemia may be associated with ileus, creating the risk of aspira-

Anesthesiology Consultants of Las Vegas, Las Vegas, Nevada, U.S.A. 
tion. Muscle strength may be impaired, and neuromuscular blockers may be slightly potentiated.

\section{Hyperkalaemia}

Hyperkalaemia is most often associated with the inability to excrete $\mathrm{K}^{+}$. Renal failure is the disease most commonly associated with hyperkalaemia. Recent reports have revealed a new danger for patients with renal dysfunction. Angiotensin inhibitors such as captopril can cause hyperkalemia when renal function is compromised. Verapamil has been reported to increase the risk of hyperkalaemia. Apart from renal failure, hyperkalaemia is almost always iatrogenic: rapid infusion of blood, rapid injection of penicillin, prolonged use of heparin, aggressive replacement of $\mathbf{K}^{+}$. The most dramatic episodes of hyperkalaemia involve shifts of $\mathrm{K}^{+}$. The administration of succinylcholine to patients with neuromuscular disorders can cause massive release of $\mathrm{K}^{+}$from skeletal muscles. It is accepted that succinylcholine depolarization can cause hyperkalaemic cardiac arrest in patients with CVA's, muscular dystrophies, burns, cord injuries, and tetanus. Some investigators have suggested that the period of susceptibility is followed by a safe time. However, there is no way of knowing when these "safe" periods have been reached.

Automaticity, conductivity, contractility, and excitability are expected to be impaired during hyperkalemia. These expectations are reflected by the classic electrocardiographic changes of hyperkalaemia. Changes progress from elevated $T$ waves, to prolongation of $P-R$ interval. Next, the QRS complex widens and the $P$ wave disappears. Final changes are wide biphasic QRS complexes evolving to fibrillation or standstill.

The following represents my opinion of how hyperkalemia should be managed.

Chronic hyperkalaemia may be well tolerated and not require treatment. When hyperkalaemia occur's acutely or when the ECG shows changes in the P-R interval or the QRS complex, treatment is necessary. The most rapid and effective therapy for hyperkalaemia is calcium chloride. This drug improves automaticity, conduction and contractility without changing the $\mathrm{K}^{+}$levels. Administering $10-20 \mathrm{ml}$ of ten per cent $\mathrm{CaCl}_{2}$ will restore cardiac excitability in approximately one to two minutes. The effect may last 15-20 minutes. This therapy is limited because of its bricf duration of action and its lack of effect on serum $\mathrm{K}^{+}$levels.

Other therapies rely on the extrarenal mechanisms. These regimens shift $\mathrm{K}^{+}$intracellularly. Standard measures include infusion of bicarbonate and glucose-insulin mixtures. A $50 \mathrm{mEq}$ bolus of $\mathrm{NaHCO}_{3}$ will shift potassium into cells in five minutes. Serum potassium is decreased for a variable period of time. Glucose-insulin infusions also shift potassium into cells. Begin therapy with $50 \mathrm{ml}$ of 50 per cent dextrose plus ten units of insulin. Maintain infusions with $10-25$ per cent dextrose and 1 unit of insulin $/ 2 \mathrm{gm}$ of dextrose. Infuse $300-500 \mathrm{ml}$ over $30-60$ minutes. In 30 minutes, serum potassium should decrease by $1.5-2.5 \mathrm{mEq}$. The decrease should be sustained for at least six hours. Dangers of therapy include volume overload, and hyperglycaemia.

I believe these measures will be supplanted by the infusions of beta $a_{2}$ agonists. Drugs such as epinephrine, ritodrine, and terbutaline have been shown to cause acute hypokalaemia. I believe these drugs will come to constitute the major therapy for hyperkalaemia.

\section{Bibliography}

Adrogue $\mathrm{HJ}$, Madias $N$. Changes in plasma potassium concentration during acute acid-base disturbances. Am J Med 1981; 71: 456-67.

Cox $M$. Sterns $R H$, Singer $I$. The defensc against hyperkalemia: the roles of insulin and aldosterone. $N$ Engl $J$ Med 1978; 299: $525-32$.

Brown MJ, Brown DC, Murphy MB. Hypokalemia from betagreceptor stimulation by circulating epinephrine. $N$ Engl J Med 1983; 309: 1414-9.

Epstein $F H$, Rosa RM. Adrenergic control of serum potassium. N Engl J Med 1983; 309: 1450-1.

Williams $M E$ et al. Impairment of extrarenal potassium dis posal by alpha-adrenergic stimulation. N Engl J Med 1984; 311: 145-9.

Harringron, JT, Isner JM, Kassirer JP. Our national obsession with potassium. Am J Med 1982; 73: 155-8

Kaplan N. Our appropriate concern about hypokalemia, Am J Med 1984; 77: 1-4.

Madias JE, Madias NE, Gavras HP. Nonanhythmogenicity of diuretic-induced hypokalemia. Arch Intern Med 1984; 144: 2171-6.

Kaplan NM et al. Potassium supplementation in hypertensive patient with diurctic-induced hypokalemia. N Engl J Med 1985; 312: 746-9.

Kassirer JP, Harringion JT. Fending off the potassium pushers. N Engl J Med 1985; 312: 785-6.

Wong $K C$ et al. Chronic hypokalemia on epinephrine-induced dysrhythmias during halothane, enflurane, or methoxyflurane with nitrous oxide anesthesia in dogs. Anesth Sinica 1983; $21: 139-46$.

Wong KC, Port JD, Steffins I. Cardiovascular response to asphyxial challenge in chronically hypokalemic dogs. Anesth Analg 1983; 62: 991-4.

Vitez TS, Soper $L$, Wong KC, Soper PG. Chronic hypokalemia and intraoperative dysrhythmias. Anesthesiology 1985; 63 : 130-3.

Shin $B$, Mackenzie MB, Helrich $M$. Hypokalemia in trauma patients. Anesthesiology 1986; 65: 90-2.

Vitez TS, Treatment of hyperkalemia with epinephrine. Anesthesiology 1986; 65: 350-1. 